Combretastatinas e seus Análogos: a Natureza como Fonte Alternativa para a Terapia do Câncer

\author{
Fraga, A. G. M.* \\ Rev. Virtual Quim., 2015, 7 (2), 765-790. Data de publicação na Web: 18 de março de 2015 \\ http://www.uff.br/rvq
}

\title{
Combretastatins and their Analogues: Nature as an Alternative Source for the Therapy of Cancer
}

\begin{abstract}
Since the identification and characterization of chemical constituents from african tree Combretum caffrum species, it took more than three decades. Among these $C$. caffrum components, combretastatin A-4 showed highlighted antineoplastic, cytotoxic and antiangiogenic profile. Its reduced bioavailability linked to its limited pharmacokinetic profile has encouraged the scientific community to propose chemical modifications in the structure of this natural product in order to overcome these limitations and to obtain therapeutically relevant compounds. In this paper we describe aspects of the structure- antitumoral activity relationships of combretastatin A-4 analogues proposed by the introduction of changes in its subunits $A, B$ and spacer.
\end{abstract}

Keywords: Câncer; combretastatins; combretastatin A-4; stilbenes.

\section{Resumo}

Desde a identificação e a caracterização dos constituintes químicos da árvore africana Combretum caffrum decorreram mais de três décadas. Dentre os componentes de $C$. caffrum a combretastatina A-4 se destaca pelo perfil de atividade antineoplásica, citotóxica e antiangiogênica. Sua reduzida biodisponibilidade atrelada a seu limitado perfil farmacocinético impulsionou a comunidade científica a propor modificações químicas na estrutura deste produto natural com $o$ intuito de contornar estas limitações e obter compostos terapeuticamente relevantes. Neste trabalho descreveremos aspectos da relação estruturaatividade antitumoral de análogos de combretastatina A-4, propostos por modificações de suas subunidades $A$, B e espaçadora.

Palavras-chave: Câncer; combretastatinas; combretastatina A-4; estilbenos.

\footnotetext{
* Universidade Federal do Rio de Janeiro, Faculdade de Farmácia, Departamento de Fármacos e Medicamentos, Av. Carlos Chagas Filho, 373, CCS, Bloco Lss, sala 24, Cidade Universitária - RJ, CEP 21941-902, RJ, Brasil.

Magmfraga@yahoo.com.br DOI: 10.5935/1984-6835.20150036
} 


\title{
Combretastatinas e seus Análogos: a Natureza como Fonte Alternativa para a Terapia do Câncer
}

\author{
Aline G. M. Fraga* \\ Universidade Federal do Rio de Janeiro, Faculdade de Farmácia, Departamento de Fármacos e \\ Medicamentos, Av. Carlos Chagas Filho, 373, CCS, Bloco Lss, sala 24, Cidade Universitária - RJ, \\ CEP 21941-902, RJ, Brasil. \\ *agmfraga@yahoo.com.br
}

Recebido em 18 de março de 2015. Aceito para publicação em 18 de março de 2015

\section{Introdução}

2. Inibição dos microtúbulos

\section{Combretastatinas}

3.1. Origem e ocorrência

3.2. Características estruturais e atividade

\section{Relação estrutura atividade antitumoral}

4.1. Anel A

4.2. Anel B

4.3. Unidade Espaçadora (linker)

\section{Considerações finais}

\section{Introdução}

Conhecido há séculos, o câncer é o termo dado ao conjunto de mais de 100 patologias que apresentam em comum o crescimento desordenado (maligno) de células que invadem os tecidos e órgãos, podendo espalhar-se (metástases) para outras partes do corpo. ${ }^{1,2}$

A Organização Mundial da Saúde (OMS) estima que, no ano 2030, são esperados 27 milhões de casos incidentes, sendo 17 milhões de óbitos e 75 milhões de pessoas convivendo com este mal. ${ }^{3,4}$
Dependendo da extensão, estágio e localização primária, o tratamento dos diversos tipos de câncer pode envolver uma série de esquemas e combinações (cirurgia, radioterapia, transplante de medula óssea ou quimioterapia). ${ }^{4,5}$

A quimioterapia é alvo de extensa pesquisa nos últimos anos com o intuito de se desenvolver novos fármacos, mais ativos, que apresentem cada vez menos efeitos colaterais, baixa toxicidade, boa biodisponibilidade e que não desenvolvam resistência. ${ }^{6}$

O principal objetivo do emprego de antineoplásicos utilizados na clínica hoje é 
eliminar as células tumorais através da inibição de alguns dos mecanismos envolvidos na divisão celular. Dentre as estruturas celulares envolvidas neste processo, os microtúbulos, filamentos intracelulares formados por subunidades alternadas de uma proteína dimérica, $\alpha$ e $\beta$ tubulina, são capazes de se polimerizardespolimerizar para formarem o fuso mitótico a fim de separarem os cromossomas corretamente durante a divisão celular (Figura 1). ${ }^{7}$

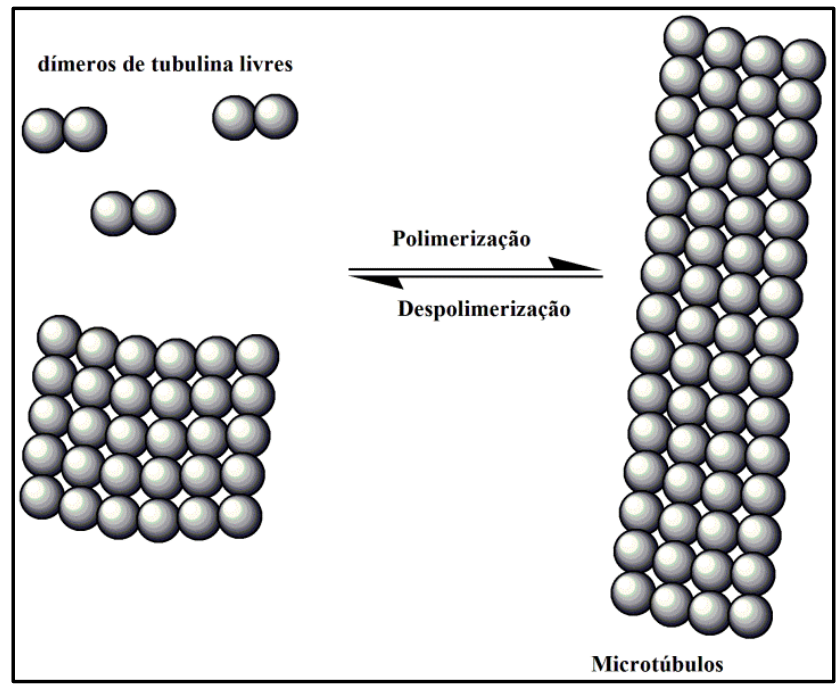

Figura 1. Equilíbrio dinâmico entre microtúbulos e dímeros de tubulina

Vários agentes empregados para o tratamento do câncer exercem sua ação rompendo esse equilíbrio, ligando-se a proteína tubulina e impedindo o processo de polimerização ou ligando-se aos microtúbulos e inibindo a sua despolimerização, estabilizando-os. Como consequência, a formação do fuso mitótico é interrompida e, por esta razão, tais compostos são denominados antimitóticos. ${ }^{5-7}$

\section{Inibição dos microtúbulos}

Os microtúbulos são o principal alvo de compostos de origem natural empregados com sucesso para o tratamento de alguns tipos de câncer, pois são extremamente importantes durante o processo de mitose celular em que os cromossomas duplicados separam-se em células filhas idênticas. Isto faz com que tais estruturas sejam apontadas como um alvo de destaque para o desenvolvimento de fármacos antineoplásicos em diferentes estágios de triagem clínica, ${ }^{8-11}$ ou já aprovados para uso na terapia do câncer, como por exemplo a vinflunina-Javlor ${ }^{\circ}, 12,13$ e 2-metoxiestradiolPanzem ${ }^{\circledR} .{ }^{14}$

Compostos que atuam ao nível dos microtúbulos ligam-se em três principais sítios na proteína tubulina, nomeados de acordo com seus principais ligantes, alterando o processo dinâmico de mitose na transição entre as fases metáfase/anáfase e consequentemente induzindo à morte celular: ${ }^{15}$

a) sítio TAXOL, no qual se liga o paclitaxel (taxol, 1; Figura 2), um dos mais importantes produtos naturais empregados na quimioterapia para o tratamento de câncer de mama, ovário e pulmões. Estes derivados estimulam 0 processo de polimerização sendo então classificados como agentes estabilizadores dos microtúbulos.

b) o sítio VINCA, onde se ligam os alcaloides de Catharanthus roseus (Vinca rosea), vincristina (2; Figura 2) e vimblastina 
(3; Figura 2), moléculas de estruturas complexas empregadas para o tratamento de leucemias/linfomas e doença de Hodgkin, respectivamente; $\mathrm{e}$

c) o sítio COLCHICINA, onde se liga o alcaloide tropolônico extraído de um açafrão venenoso Colchicum autumnale L., colchicina (4; Figura 2) e podofilotoxinas (5; Figura 2); ambos inibem o processo de polimerização sendo classificados como agentes desestabilizadores dos microtúbulos. ${ }^{6,16}$

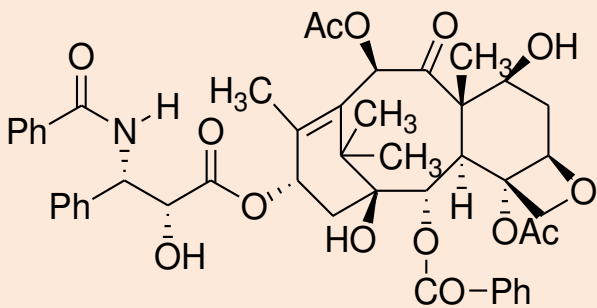

paclitaxel (1)<smiles>COc1cc2c(c(OC)c1OC)-c1ccc(OC)c(=O)cc1C(NC(C)=O)CC2</smiles>

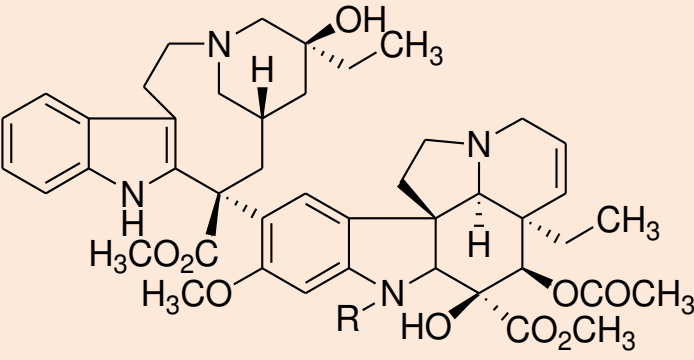

$\mathrm{R}=\mathrm{CHO}$ vincristina (2) $\mathrm{R}=\mathrm{CH}_{3}$ vimblastina (3)<smiles>COc1cc([C@H]2c3cc4c(cc3[C@@H](O)[C@@H]3COC(=O)[C@H]23)OCO4)cc(OC)c1OC</smiles>

Figura 2. Estrutura dos ligantes de diferentes sítios ativos da proteína tubulina

Os sítios taxol e vinca, localizam-se na subunidade $\beta$-tubulina, o primeiro no interior de uma bolsa hidrofóbica ${ }^{6,17}$ e o segundo próximo ao sítio de ligação do $\mathrm{GTP},{ }^{18}$ enquanto o sítio colchicina localiza-se entre as subunidades $\alpha$ e $\beta$ desta proteína. ${ }^{19}$

Apesar das classes descritas acima apresentarem como fato comum a capacidade de interromperem o ciclo de polimerização-despolimerização da tubulina, sabe-se que substâncias que apresentam ação antineoplásica baseada somente na inibição deste ciclo são ineficientes em células que não se encontram em fase de divisão celular, podendo assim sobreviver e adquirir resistência aos fármacos. A interrupção do suprimento de sangue dos tumores torna-se necessário e é um alvo importante para o desenvolvimento de compostos antineoplásicos, uma vez que resulta na morte da célula, independente da fase de divisão celular. ${ }^{20}$

Entretanto, a ação de agentes antiangiogênicos de forma isolada é eficiente sobre tumores centrais, porém não produz efeito significativo em tumores periféricos sendo, portanto, mais eficientes quando aplicados em uma terapia associada à radioterapia e fármacos citotóxicos. ${ }^{21}$

A colchicina (4), primeiro agente desestabilizador da tubulina a ser descoberto, diferencia-se dos alcaloides derivados da vinca e dos taxoides, pela sua capacidade de atuar na rede vascular que irriga o tumor. Seu emprego na clínica para o tratamento de neoplasias é limitado por sua elevada toxicidade, ${ }^{20}$ apesar de ser amplamente empregada na medicina tradicional para tratamento da gota. ${ }^{22}$ 
Pode-se, assim, constatar que o desenvolvimento de compostos estruturalmente relacionados à colchicina, que atuem no mesmo sítio ativo na tubulina e que apresentem uma ação dual (antiangiogênicos e citotóxica) é extremamente atraente. ${ }^{20,22}$

As combretastatinas, estilbenos de origem natural, destacam-se como uma classe promissora de agentes antimitóticos que tem despertado o interesse da comunidade científica devido a sua ação antivascular e antiproliferativa. ${ }^{23}$ Sua aplicação terapêutica é limitada pela sua elevada toxicidade, porém alguns relatos na literatura descrevem que alguns de seus derivados alcançaram etapas de fase clínica avançadas. ${ }^{24}$ Tais resultados, aliados a sua estrutura química simples, fomentam programas de pesquisa inovadores para a descoberta de inibidores do sítio da colchicina que sejam terapeuticamente úteis. ${ }^{25,26}$
O objetivo deste artigo é descrever algumas das principais alterações estruturais realizadas nas combretastatinas, através de dados da literatura, ${ }^{24,27}$ com o intuito de estimular novas pesquisas para 0 planejamento de agentes antitubulínicos para o tratamento de neoplasias.

\section{Combretastatinas}

\subsection{Origem e ocorrência}

As combretastatinas são um grupo de compostos isolados por Pettit e colaboradores a partir da casca e do caule da árvore pertencente à família Combretaceae, Combretum caffrum, nativa das margens dos rios na Província do Cabo Oriental, África do Sul. $^{28}$
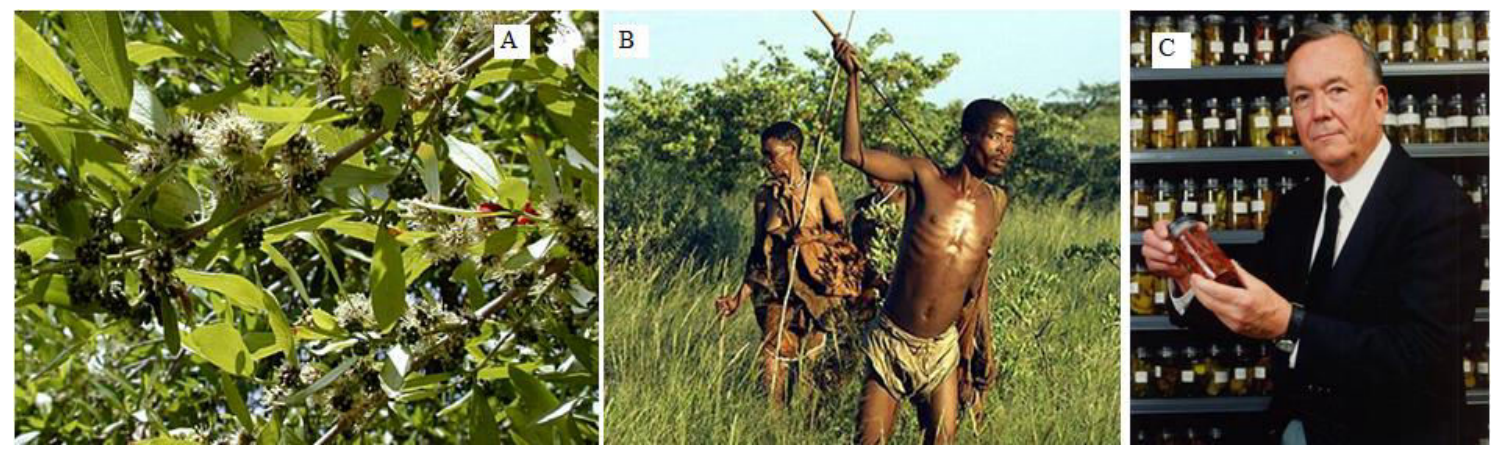

Figura 3. A- Árvore Combretum caffrum ; B- Caçadores da tribo San; C- Professor George R. Pettit. (Adaptado de http://anint.sbq.org.br)

Outras espécies do gênero Combretum são empregadas na medicina popular africana e indiana para uma série de finalidades, incluindo purgação, ação curativa e tratamento da hanseníase e câncer. ${ }^{28,30} \mathrm{Em}$ Gana, as raízes de uma outra espécie, Combretum mucronaturn, são empregadas como anti-helmíntico. ${ }^{31}$ Dados históricos indicam que árabes já negociavam as cascas de Combretum caffrum com o povo nômade San, também chamado de Bushman, devido as suas propriedades como tônico, e a sua capacidade de gerar sensação de bem estar.
Entretanto, a casca da raiz (também conhecido como Bushwillow, salgueiro bushveld e 'rooiblaar'), devido a sua toxicidade foi usada pelo povo Zulu, como veneno para as suas lanças e como um amuleto para se protegerem dos inimigos (Figura 3).

O Professor George R. Pettit, diretor do Instituto de Pesquisa do Câncer na Universidade Estadual do Arizona (EUA), juntamente com seus colegas, extraíram de Combretum caffrum outras substâncias com atividade superior a apresentada pela 
combretastatina. ${ }^{32-35}$ Dentre esse grupo de compostos, a combretastatina A-4 (CA4, 7; Figura 4) se destacou por apresentar relevantes propriedades anti-mitóticas e angiogênicas. ${ }^{28,32,36-40}$

\subsection{Características estruturais e atividade}

A combretastatina (6) é estruturalmente semelhante à colchicina (4) (Figura 4), uma vez que ambas apresentam $O$ anel trimetoxifenila em (A) e o anel B da combretastatina (6) é similar ao anel tropolônico (C) da colchicina. ${ }^{28,40}$ A CA4 (7) por sua vez é similar a combretastatina (6) diferindo apenas pela presença da ponte etilênica não substituída com configuração relativa cis que resulta da desidratação de (6).

Adicionalmente, a CA4 (7) é classificada como agente antiangiogênico, pois apresenta a capacidade de interagir rapidamente de modo especifico com a vascularização anormal dos tumores, resultando em um colapso vascular e necrose tumoral. ${ }^{41}$ Sugere-se que essa atividade seja mediada através da sinalização caderina-endotélio vascular atuando através de dois mecanismos, o primeiro impedindo a formação de novos vasos que alimentará o tumor e o segundo, atuando em vasos já formados. ${ }^{41,42}$

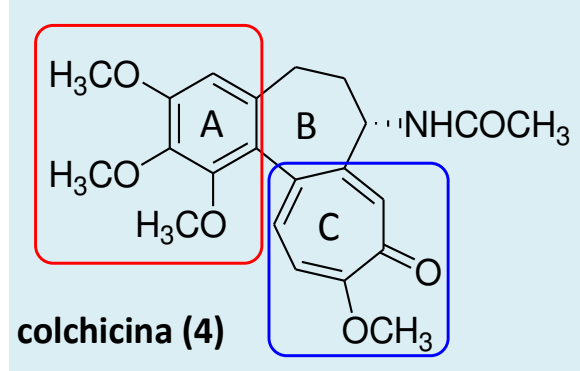

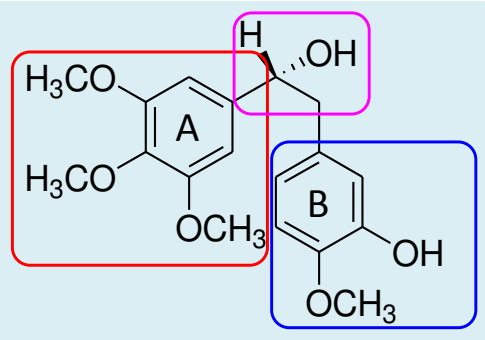

combretastatina (6)

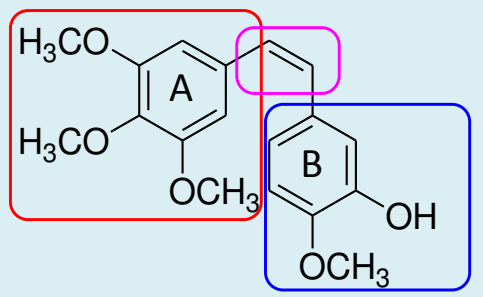

combretastatina A-4 (7)

Figura 4. Relação estrutural entre as subunidades da colchicina (4), combretastatina (6) e CA4 (7)

A simplicidade estrutural da CA4 (7), aliada às suas excelentes atividades antitumoral e antiangiogênica, encorajou a comunidade científica a investigar seus análogos estruturais, e um grande número de estudos envolvendo síntese e avaliação da atividade biológica de seus derivados. ${ }^{43-45}$

Apesar de a destacada atividade antitumoral de (7), o seu uso clínico é limitado por alguns fatores: baixa biodisponibilidade, reduzida solubilidade em pH fisiológico, reduzido tempo de meia vida e isomerização da ligação dupla entre os dois anéis aromáticos, in vivo, que acarreta a redução de afinidade pela proteína alvo e, consequentemente, perda de sua atividade citotóxica. ${ }^{27,38,41,46,47}$ 


\section{Relação estrutura atividade antitumoral}

Com o intuito de contornar as limitações farmacocinéticas apresentadas pela CA4 (7) foram realizadas muitas modificações nos anéis aromáticos $\mathrm{A}$ e $\mathrm{B}$ ou na ponte etilênica da sua estrutura. Algumas delas, juntamente com as suas principais contribuições sobre o perfil de atividade serão, a seguir, ilustradas.

\subsection{Anel A}

Inicialmente, acreditava-se que a presença do anel trimetoxilado era essencial para a que se obtivesse uma atividade citotóxica relevante e um efeito antitubulina adequado. Isto era devido principalmente a: ocorrência deste grupamento em outros compostos antitubulínicos de origem natural como podofilotoxina (5), colchicina (4) e esteganacina (8); $i^{13,48}$ a potência de CA4 (7) comparada a CA3 (9) em que o grupo metoxila em meta é substituído por uma hidroxila, ${ }^{40}$ e a trabalhos da literatura que indicavam que a presença de anel aromático sem substituinte ou sem a presença do grupamento metoxila nas posições meta ou para acarretavam perda de potência. ${ }^{49}$

Adicionalmente, Gaukroger e colaboradores concluíram que fatores estéricos podem estar envolvidos na acomodação desta subunidade no sitio ativo da proteína, uma vez que a substituição por grupamentos volumosos, como etoxila, acarretava a perda da atividade citotóxica. ${ }^{50}$ O mesmo foi observado com a inserção do grupamento fenantrenila. ${ }^{51}$

Com o intuito de favorecer interações hidrofóbicas que ocorrem com o sítio ativo, algumas substituições por grupos de elevada lipofilicidade foram realizadas. A presença de subunidades como naftila acarretou redução da citotoxicidade enquanto a introdução do grupo trimetilfenila gerou um composto com perfil citotóxico semelhante, mas que inibe seletivamente a tubulina. ${ }^{50,52}$

A substituição das posições das metoxilas de (7) pela ponte metilenodioxila, resultando na combretastatina A-2 (10), reduz consideravelmente a capacidade citotóxica deste composto, da mesma forma que a troca de posição das metoxilas de $3,4,5$ para $2,3,4.32,38$

O composto fluorcombretastatina (11) apresentou atividade antitubulina equivalente a (7) com pequena perda de potência, enquanto a troca por átomos mais volumosos como cloro e bromo diminuiu a atividade citotóxica e antitubulina. ${ }^{53}$

Outros grupos funcionais foram inseridos em substituição ao anel $A$ com o intuito de avaliar a sua contribuição no reconhecimento molecular pela proteína alvo. Fortin e colaboradores desenvolveram uma série de agentes antimicrotúbulos denominados CEU, $N$-fenil- $N^{\prime}$-(2-cloroetil)urea, capazes de se ligarem covalentemente ao sítio da colchicina através de uma substituição nucleofílica envolvendo o farmacóforo $\mathrm{N}$-2-cloroetilureia, enquanto ao nível das combretastatinas essa interação é eletrostática. ${ }^{54}$ Os híbridos CA4-CEU (12) se mostraram citotóxicos em células tumorais através da interação covalente com o sítio ativo da colchicina. ${ }^{55,56}$

Arthuis e colaboradores investigaram a possível troca da fenila do anel A por uma subunidade aromática mais volumosa. Vários derivados 2-aroiltrimetoxindóis foram preparados e a interação com a proteína alvo foi investigada, constatando-se que o padrão de substituição do anel indólico e a presença de um pequeno grupo hidrofóbico na posição para do anel B são importantes para esta interação. O composto (13) se destacou como um protótipo promissor de inibidores da polimerização da tubulina. ${ }^{57}$ 


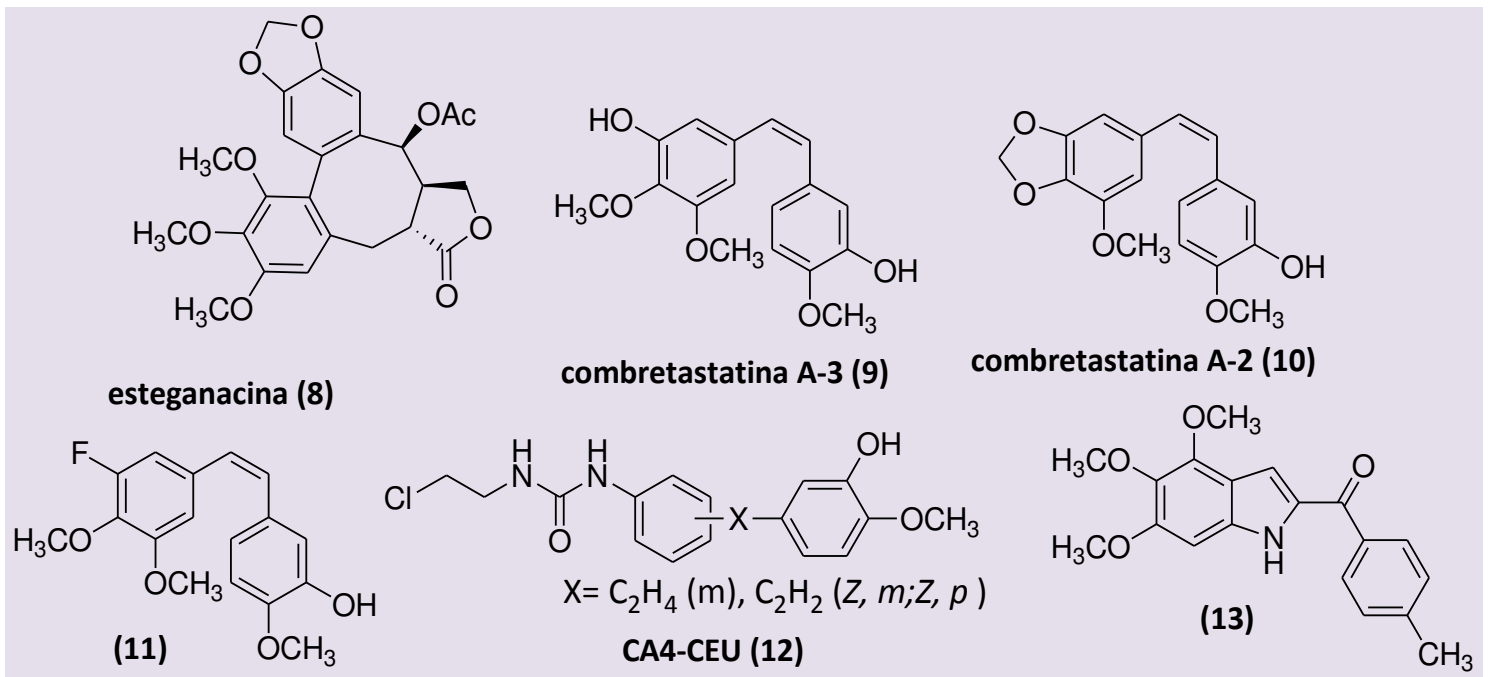

Figura 5. Compostos com alteração no anel A da CA4 (7)

\subsection{Anel B}

Os relatos na literatura descrevendo modificações no anel B das combretastatinas confirmam o credo que se teve por muito tempo, que esta região da estrutura do produto natural era a única que poderia ser modificada e ainda fornecer compostos ativos. Tais modificações de forma geral podem ser incluídas em três grupos: modificações dos substituintes do anel, substituição do anel fenila por heterociclos e a introdução de anéis aromáticos sem substituintes.

\subsubsection{Modificações dos substituintes do} anel

A introdução de grupamentos nesta região das combretastatinas pode contribuir consideravelmente para entender o tipo de interação que esta subunidade realiza com o sítio ativo da proteína e o impacto sobre o perfil farmacológico.

Cushman e colaboradores observaram que a presença do grupo metoxila na posição para se mostra essencial para a atividade antitumoral, diferentemente da presença de grupos oxigenados na posição meta. ${ }^{49}$

A observação de que a remoção do substituinte presente na posição meta trazia consequências mínimas para a atividade acarretou em modificações isostéricas deste grupo pelo átomo de flúor (14), cuja elevada capacidade retiradora de elétrons poderia impedir reações de metabolização oxidativa neste anel, com consequente melhora de seu perfil farmacocinético. ${ }^{38,58}$ Este composto apresentou destacada atividade citotóxica apesar de problemas quanto a sua solubilidade. ${ }^{58} \mathrm{~A}$ introdução de um átomo de halogênio mais volumoso como bromo (15) acarretou na redução da atividade citotóxica em cerca de 10 vezes sem comprometer o perfil antitubulínico, indicando que fatores estéricos também são importantes para a interação desta subunidade com o sítio ativo da proteína tubulina. ${ }^{59} \mathrm{~A}$ mudança de posição do grupamento metoxila em para para a posição meta ou ainda a inserção de grupamentos retiradores de elétrons, como o grupo nitro, diminuem a atividade citotóxica. ${ }^{47,59,60}$

Vários grupos de pesquisa investigaram a troca isostérica da hidroxila em meta pelo grupamento isóstero amina (16) e constataram que tais compostos além de outros derivados aminados de CA4 apresentam uma atividade antitumoral levemente superior (cerca de $2 \mathrm{x}$ ) sobre (7), enquanto que a substituição pelo grupamento nitro reduz a atividade em ca. 
$5 x .^{61}$

A hidroxila fenólica quando substituída pelo grupamento ácido borônico (17) fornece um composto com melhor perfil de solubilidade e elevada atividade antitubulínica e citotóxica. ${ }^{62} \mathrm{O}$ grupamento azida também foi introduzido nesta posição e, apesar de não ser um grupo farmacologicamente atraente, por suas características toxicofóricas, ainda manteve o perfil de atividade. ${ }^{60}$

A substituição do grupamento metoxila na posição para por grupamentos etoxila ou propoxila leva a perda de atividade, indicando que fatores estéricos podem contribuir para a redução da atividade destes compostos. O átomo de oxigênio parece ser fundamental para a atividade, pois a troca pelo átomo de enxofre gera um produto com reduzida atividade, provavelmente devido à perda da capacidade de atuar através de interações de hidrogênio; a introdução de grupos metila ou do átomo de cloro fornece compostos menos citotóxicos com elevada ação antitubulina. ${ }^{38}$
Adicionalmente, a troca da hidroxila de meta pelo grupo dimetilamina (18) reduz em até 10x a atividade e exerce pouca influência sobre a polimerização da tubulina. ${ }^{38}$

Tais dados indicam que o
grupamento metoxila parece ser fundamental para atividade citotóxica, mas não essencial para ação antitubulina.

A presença de um grupo hidroxila em orto no produto natural combretastatina A-1, CA1 (19) levou a investigação da contribuição dos substituintes inseridos nesta posição. Observou-se que tais substituições poderiam comprometer o perfil farmacológico proposto, uma vez que se poderia gerar compostos restritos conformacionalmente. ${ }^{63}$ A introdução de um átomo de cloro no derivado (20) reduziu sua atividade em mais de $1000 x$, não diferindo quanto a ação antitubulina e a introdução de um grupamento amina em orto gerou potenciais candidatos para ensaios pré-clínicos devido à sua potente inibição da tubulina e capacidade de interromper o fluxo sanguíneo em tecidos tumorais. ${ }^{64}$

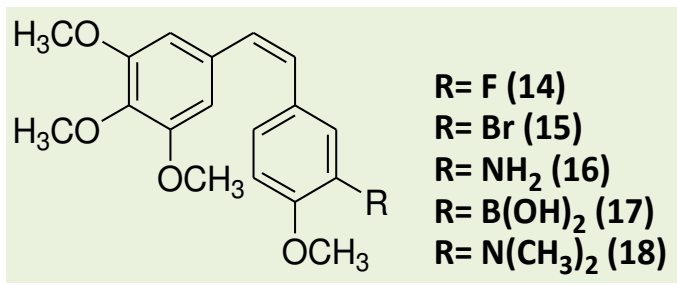

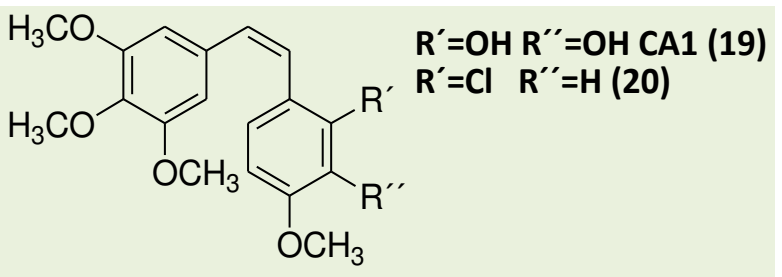

Figura 6. Compostos com alteração no anel B da CA4 (7)

O inadequado perfil de solubilidade e biodisponibilidade de (7) levou ao desenvolvimento de derivados com grupos capazes de aumentar a solubilidade e que pudessem contornar tais características, como os derivados fosfato (CA4P, 21) e amino (22). Tais compostos apresentam ação antitumoral quando administrados sozinhos ou em combinação com outras formas de tratamento de neoplasias, como com outros quimioterápicos, radioimunoterapia e agentes antiangiogênicos, atuando com elevada eficácia e rapidez sobre a vasculatura tumoral. ${ }^{65,66}$ 
<smiles>COc1ccc(/C=C\c2cc(OC)c(OC)c(OC)c2)cc1O[R6](=O)[O-]</smiles>

Figura 7.Derivado fosfato (21) e amino derivado (22)<smiles>COc1ccc(/C=C\c2cc(OC)c(OC)c(OC)c2)cc1N</smiles>

(22)
4.2.2. Substituição do anel fenila por heterociclos

A substituição do átomo de carbono da fenila do anel B por um heteroátomo com pares de elétrons livres pode acarretar alteração na solubilidade ou na interação com a proteína alvo. As modificações por anéis heterociclos podem ser acompanhadas também por modificação no linker e serão discutidas no item seguinte.

Relatos na literatura indicam que a introdução do anel piridina nesta região gera compostos cuja atividade é influenciada pela posição adotada pelo átomo de nitrogênio. $O$ composto substituído na posição 3 (23) apresenta potente ação citotóxica e antitubulínica, o que não acontece com compostos substituídos na posição $2 .^{67}$<smiles>COc1ccc(/C=C\c2cc(OC)c(OC)c(OC)c2)cn1</smiles>

Figura 8. Introdução de heteroátomo no anel B da CA4 (7)

4.2.3. Introdução de aromáticos sem substituintes

A completa remoção dos grupamentos presentes no anel B compromete o perfil de atividade dos derivados de (7).

A introdução de um anel naftaleno não- substituído nesta região gera um composto que apresenta de 4-5x menor atividade citotóxica e antitubulínica. ${ }^{68} \mathrm{~A}$ introdução do heterociclo quinolina no derivado (24), reforça a importância da posição adotada por este heteroátomo, e apesar de melhorar o perfil de solubilidade levou a uma redução do perfil de citotoxicidade de $70 x .^{69}$<smiles>COc1cc(/C=C\c2ccc3cccnc3c2)cc(OC)c1OC</smiles>

Figura 9. Introdução de heterociclo no anel B da CA4 (7) 
Apesar da substituição em orto ser menos explorada, esta posição pode ser atraente para a inserção de grupos capazes de introduzir restrições conformacionais que contribuem para o incremento da atividade. $^{62,71,72}$

\subsection{Unidade espaçadora (linker)}

A isomerização da ligação dupla, ou linker, entre os anéis aromáticos A e B da CA4 através de ação do calor, luz e meios próticos, acarreta na diminuição drástica da atividade. Isso levou a intensa pesquisa e desenvolvimento de novos derivados com estabilidade química da configuração cis e menos propensa metabolização. ${ }^{27,37,41,46,47,59,73,74}$ Para tal, os derivados descritos na literatura podem ser divididos basicamente em dois grandes grupos, aqueles oriundos da modificação do sistema insaturado que podem acompanhar ou não a modificação do anel $B$ e aqueles provenientes da introdução de heterociclos.

\subsubsection{Modificação no sistema insaturado}

A substituição da ponte etilênica por uma carbonila levou a obtenção da fenstatina (25) por Pettit e colaboradores. Este derivado benzofenônico apresenta atividade antitubulina semelhante a (7) e uma discreta redução da citotoxicidade. ${ }^{75}$ Este mesmo perfil de atividade foi observado quando foram introduzidos no lugar do anel $B$, o núcleo indol (26) e a subunidade 3-amino-4metoxifenila (27). ${ }^{75}$

Ducki e colaboradores propuseram a inserção de um sistema carbonilado $\alpha, \beta$ insaturado (28) para a obtenção de compostos citotóxicos. ${ }^{72}$

A presença do grupamento amida como linker acarreta uma significante perda das atividades citotóxica e antitubulínica. Já o composto (29) com o grupo sulfonato como linker tem atividade antiproliferativa na faixa nanomolar. ${ }^{76}$<smiles>COc1ccc(C(=O)c2cc(OC)c(OC)c(OC)c2)cc1OC</smiles>

(25)<smiles>COc1ccc2c(C(=O)c3cc(OC)c(OC)c(OC)c3)c[nH]c2c1</smiles><smiles>COc1ccc(C(=O)c2cc(OC)c(OC)c(OC)c2)cc1N</smiles><smiles>COc1ccc(/C=C/C(=O)c2cc(OC)c(OC)c(OC)c2)cc1O</smiles><smiles>COc1ccc(S(=O)(=O)Oc2cc(OC)c(OC)c(OC)c2)cc1N</smiles>

Figura 10. Derivados oriundos da modificação do linker da CA4(7)

A introdução da subunidade $N$ acilidrazona (NAH) descrito por Amaral e colaboradores acarretou em substancial alteração no arranjo espacial entre os anéis $A$ e $B$, em que o derivado (30) se destacou pela capacidade de inibir a polimerização da tubulina, com amplo perfil citotóxico e seletividade superior a (7). ${ }^{77}$

Nakamura e colaboradores introduziram um átomo de silício como linker e o derivado (31), preparado por estes autores, apresentou atividade antitubulina e citotóxica comparáveis a (7), além de melhor perfil físico-químico. Esse resultado sugere 
que o silício possa atuar como bioisóstero da ponte etilênica. ${ }^{78}$

Análogos apresentando a subunidade hidroxietila foram desenvolvidos por Lee e colaboradores. Estudos de modelagem molecular indicaram que o derivado (32), que apresenta os mesmos substituintes de (7), adota uma conformação torcida que mimetiza a do produto natural. Tal composto apresenta destacada atividade antitubulina e citotóxica, além de maior solubilidade em água. ${ }^{79}$<smiles>COc1cc(C(=O)N/N=C/c2ccccc2)cc(OC)c1OC</smiles><smiles>COc1ccc([SiH](C)c2cc(OC)c(OC)c(OC)c2)cc1O</smiles><smiles>COc1ccc(C=C(c2cc(OC)c(OC)c(OC)c2)C(C)O)cc1O</smiles>

Figura 11. Derivados com substituição do linker da CA4 (7)

\subsubsection{Introdução de anel}

A introdução de anel em substituição a ponte etilênica traz vantagens por não permitir a isomerização da ligação dupla, podendo favorecer interações devido a eventual presença de subunidade heterocíclica.

Dados cristalográficos da estrutura de raios-x da tubulina complexada com o derivado de CA4, DAMA-colchicina disponível no protein data bank (PDB), ${ }^{62}$ revelam a não coplanaridade da ponte etilênica com os anéis $A$ e $B$. Esses anéis se mostram levemente torcidos o que pode explicar a ausência de atividade de alguns derivados de (7), por estes não serem capazes de se ligar a tubulina como acontece com o anel pirazola (Figura 12). ${ }^{41,48,80,81}$

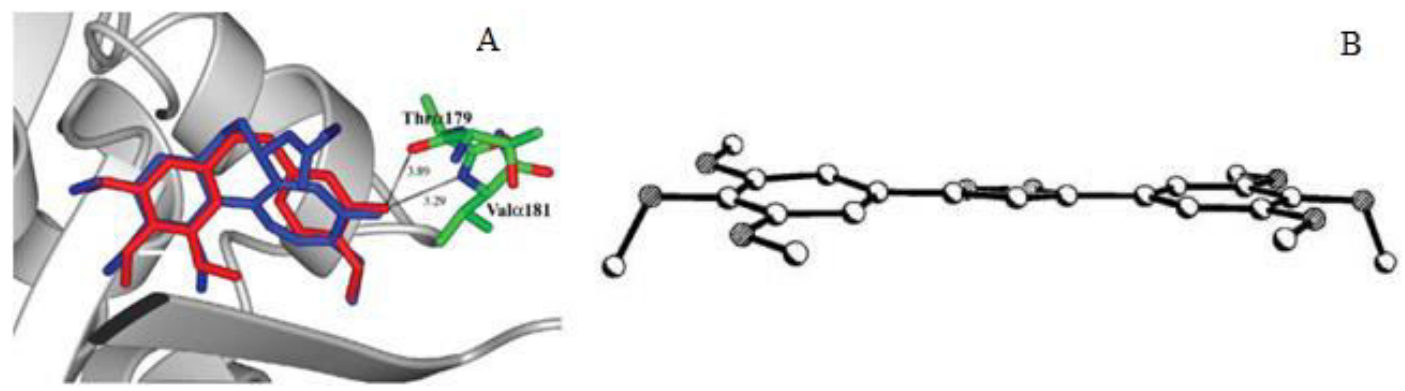

Figura 12. A-Modo de interação da DAMA-colchicina (azul) e CA4 (7, vermelho) com a proteína tubulina presente no PDB (1SA0) (Reprodução da ref. 62 com autorização Copyright $($ ) 2005, Elsevier, UK); B-Planaridade do derivado pirazola de CA4 (7) (Reprodução da ref. $81 \mathrm{com}$ autorização Copyright@ C 2005, Elsevier, UK) 
Anéis como furanona, ${ }^{82,83,}$ imidazola, ${ }^{84}$ triazola, ${ }^{85}$ azetidinona, ${ }^{86}$ pirazolina, ${ }^{87}$ cicloexenona, ${ }^{88}$ 1,3-dioxolano, ${ }^{89}$ furazan1,2,5-oxadiazola, ${ }^{91}$ heteroarilcumarina, ${ }^{91}$ 3aroil-6-metoxindola, ${ }^{92}$ 2-amino-1,3-tiazol-, 1,3-tiazola, 1,2,4-triazola, e tetrazola, ${ }^{93}$ geraram derivados capazes de causarem a despolimerização da tubulina, com variados graus de potência citotóxica.

A introdução do grupamento $\beta$-lactama foi proposta por Carr e colaboradores. ${ }^{94} \mathrm{O}$ derivado (33) foi identificado como o mais ativo da série, com potência antitumoral em escala nanomolar contra alguns tipos de câncer e atividade antitubulina semelhante a de (7). Estudos de modelagem molecular indicam que o mesmo modo de interação dos anéis $A$ e $B$ de (7) foi observado para (33), confirmando esta subunidade como um linker útil para garantir o arranjo cis entre as subunidades aromáticas deste composto. ${ }^{95}$

Um dos desafios para o desenvolvimento de novos derivados de (7) é contornar seus problemas de solubilidade. Com o objetivo de obterem compostos mais solúveis, Lee e colaboradores propuseram uma série de derivados 1,2,3,4-tetraidro-2-tioxopirimidina. Os compostos (34 e 35) mostraram serem os mais ativos da série, apesar de suas atividades serem inferiores a de (7). A atividade antitumoral destes compostos semelhantes estruturalmente a (7), foi justificada pela conformação torcida da estrutura de (35) resultante do impedimento estérico causados pelos grupos metoxila dos anéis aromáticos. ${ }^{41}$<smiles>COc1ccc(C2CC(=O)N2c2cc(OC)c(OC)c(OC)c2)cc1O</smiles>

(33)<smiles>COc1ccc(C2C=C(c3cc(OC)c(OC)c(OC)c3)NC(=S)N2)cc1O</smiles>

(34)<smiles>COc1cc(OC)c(C2C=C(c3cc(OC)ccc3OC)NC(=S)N2)c(OC)c1</smiles>

(35)

Figura 13. Derivados com anéis heterociclos na região do linker da CA4 (7)

Derivados híbridos de (7) e do alcaloide marinho lamelarina $T$ (36) foram desenvolvidos por Banwell e colaboradores através da introdução do anel pirrol como linker. Os compostos (37) e (38), semelhantes estruturalmente a (7), apresentaram atividades antimitótica e citotóxica significativas, porém inferiores a CA4. ${ }^{95}$<smiles>COc1ccc(-c2c3n(c4c(=O)oc5cc(O)c(O)cc5c24)CCc2c-3cc(OC)c(OC)c2OC)cc1O</smiles>

(36)<smiles>COC(=O)c1cc(-c2ccc(OC)c(O)c2)c(-c2cc(OC)c(OC)c(OC)c2)[nH]1</smiles>

(37)<smiles>COC(=O)c1cc(-c2cc(OC)c(OC)c(OC)c2)c(-c2ccc(OC)c(OC)c2)[nH]1</smiles>

(38)

Figura 14. Derivados híbridos de (7) e do alcaloide marinho lamelarina T (36) 
Na série de compostos apresentando a subunidade 1,3,4-oxadiazolina, o derivado (39) se destacou por sua potente ação antiproliferativa e a manutenção dos efeitos antitubulínicos. ${ }^{96}$

Alterações na ponte etilênica seguido de alteração também no anel B são descritas na literatura. Uma série de novos análogos benzo[b]imidazóis foram desenvolvidos por Zhou e colaboradores. O derivado (40) e alguns de seus análogos foram os mais ativos da série, exibindo potente atividade antitumoral em concentrações na faixa de nanomolar. ${ }^{97}$<smiles>CC(=O)N1N=C(c2ccc3ccccc3c2)OC1c1ccc2ccccc2c1</smiles>

(39)<smiles>COc1cc(-c2ncoc2-c2ccc(OC)c3[nH]cnc23)cc(OC)c1OC</smiles>

(40)

Figura 15. Derivado obtido pela introdução de anel oxadiazolina na região do linker e modificação do linker e do anel B

Vários compostos análogos de respectivas referências são apresentados na combretastatinas preparados por diferentes Tabela 1. estratégias de química medicinal e as

Tabela 1. Exemplos de estruturas gerais de diferentes análogos de combretastatinas descritos na literatura

41


Fraga, A. G. M.

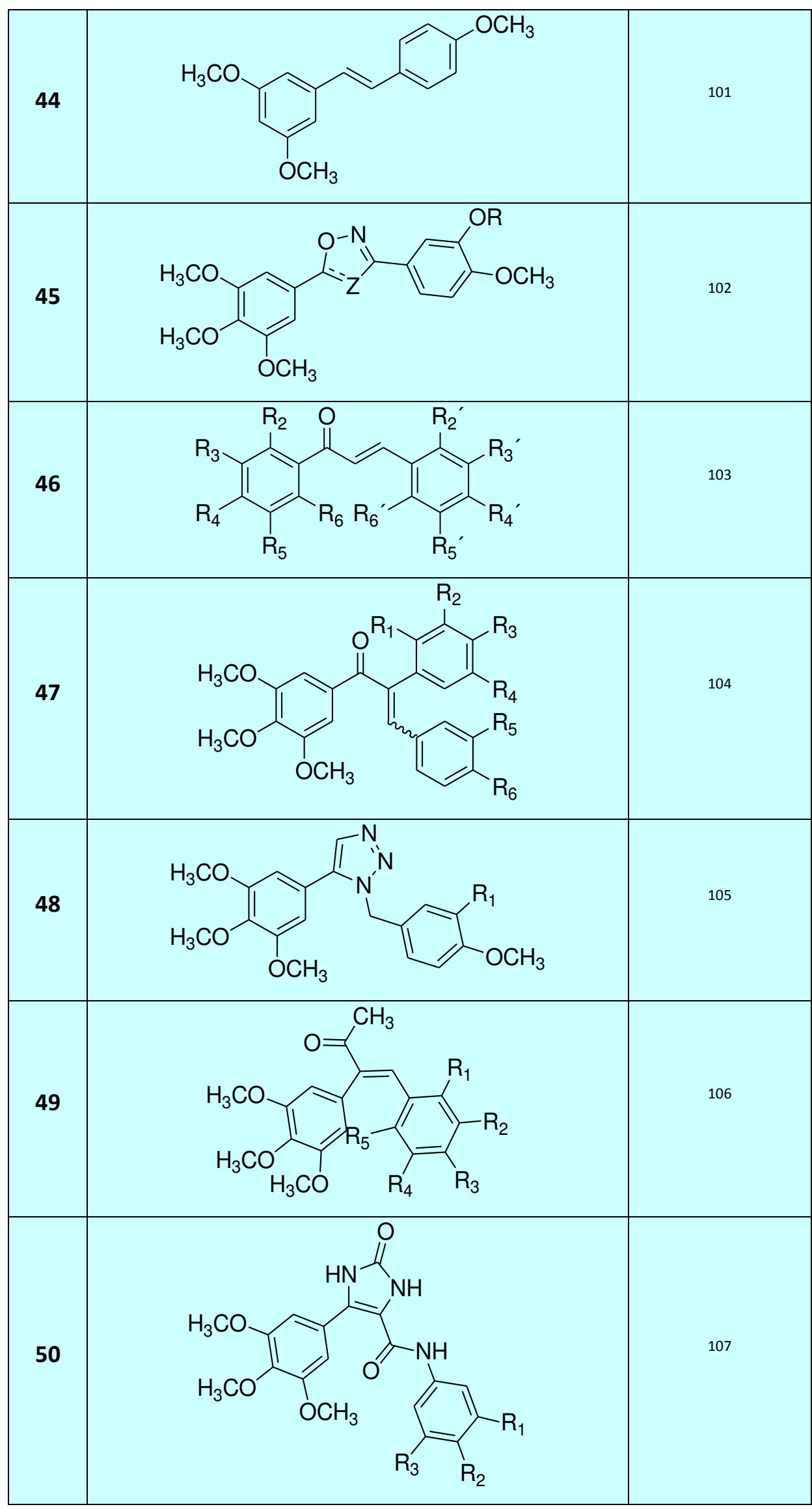




(25)




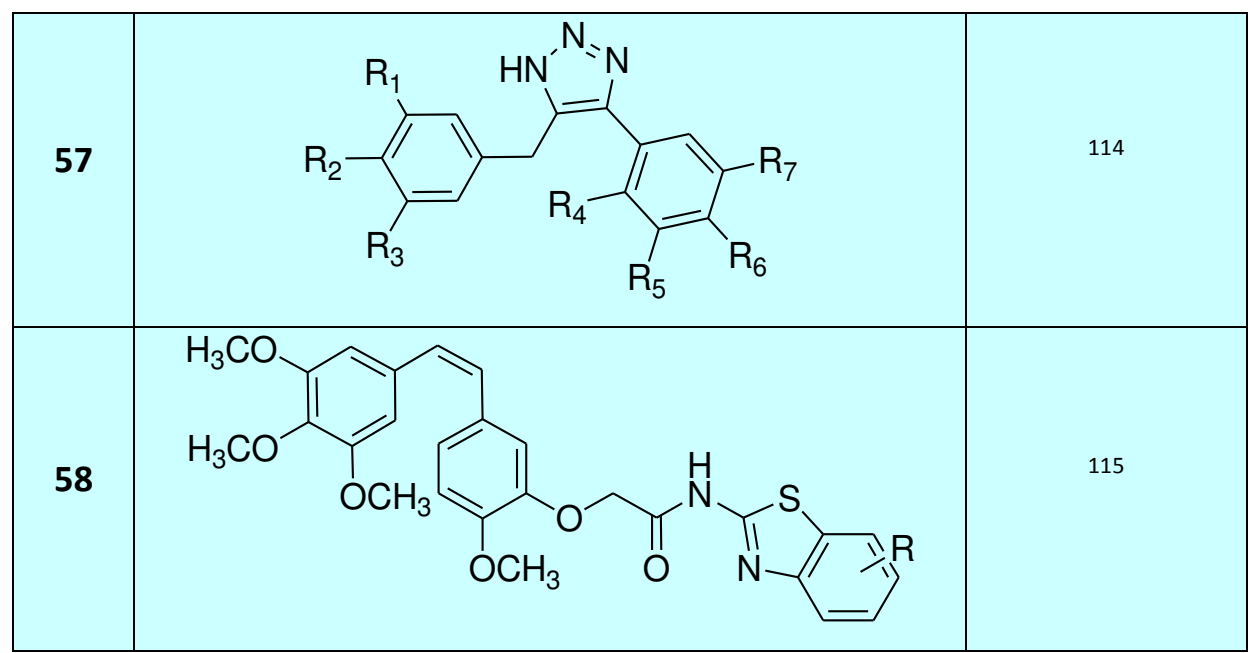

\section{Considerações finais}

Mais de três décadas se passaram desde o isolamento dos constituintes químicos bioativos de Combretum caffrum. A combretastatina A-4 (CA4, 7), isolada de C. caffrum, continua sendo um protótipo de destaque para o desenvolvimento de novos compostos que visem o tratamento de diferentes tipos de câncer.

A introdução de substituintes no anel A de (7) descritos na literatura indica que a presença da subunidade aromática trimetoxilada é importante para a atividade antitubulina, porém não é essencial. Dependendo do tipo de substituição nesta subunidade de CA4, pode-se privilegiar a atividade antitubulínica ou citotóxica.

O estudo das diferentes modificações realizadas no anel $B$ de (7) indica que dependendo do grupo introduzido, pode ocorrer à otimização da atividade citotóxica ou da atividade antitubulínica. Visando a otimização da atividade citotóxica, o grupo metoxila deve ser inserido na posição para do anel aromático da subunidade B de CA4 (7). Grupamentos doadores de elétrons (amina) ou retiradores (F) podem ser inseridos na posição meta, porém tais substituintes precisam ter volumes comparáveis ao da hidroxila.

Na região de ligação entre os anéis $A$ e $B$ de (7), observa-se que uma das principais funções da introdução de anéis aromáticos é garantir que a conformação deste novo derivado seja aquela que permita o encaixe ideal com a proteína alvo, i.e. tubulina, favorecendo a vicinalidade dos anéis $A$ e $B$, uma vez que a conformação relativa cis é essencial para a atividade destes compostos.

A introdução de anéis heterociclos ou a simples inserção de substituintes pode ser guiada pelo conhecimento do sítio ativo da proteína alvo, em um processo chamado pelos químicos medicinais de planejamento baseado na estrutura do receptor.

Pelo exposto, conclui-se que várias modificações podem ser ainda propostas com base na estrutura da combretastaina A-4 (7), com o intuito de contornar sua reduzida solubilidade, biodisponibilidade e tempo de meia-vida. Na Figura 14 encontra-se um resumo da relação estrutura-atividade da ação antitubulínica dos compostos derivados de CA4 (7) descritos neste trabalho. 


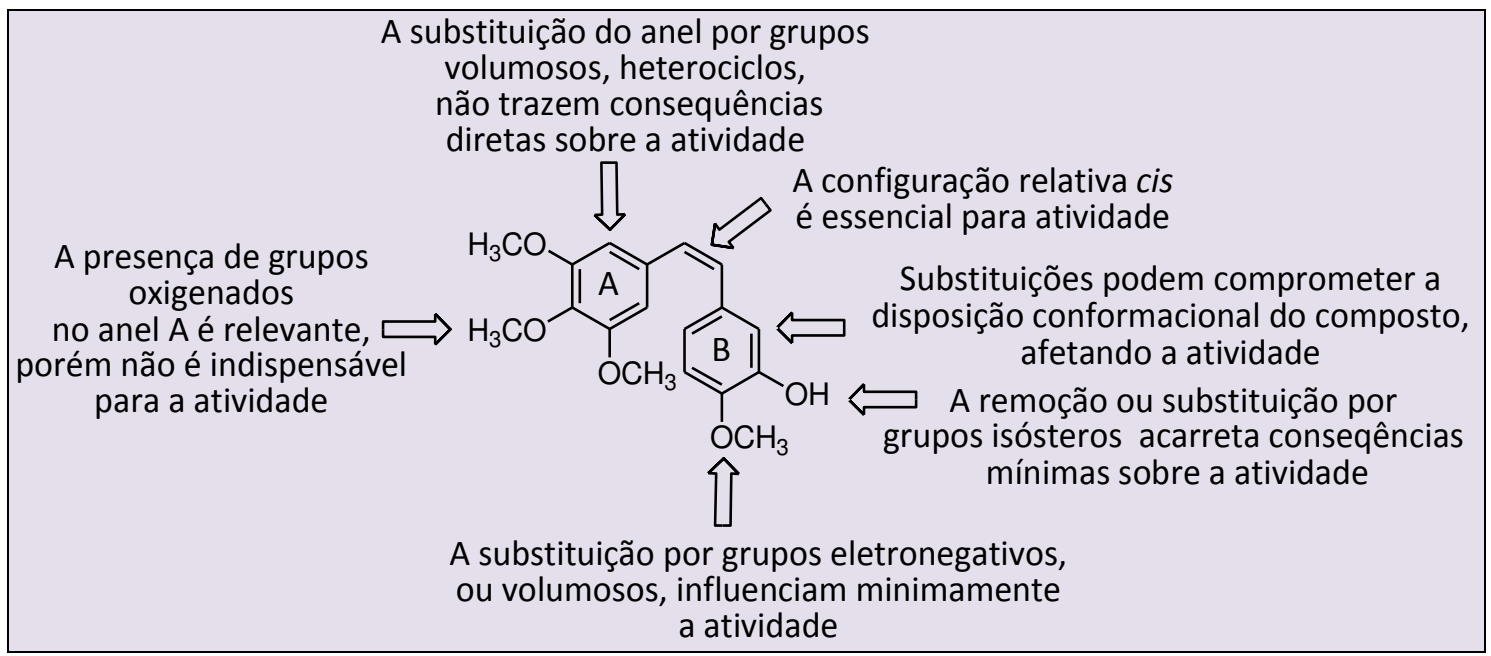

Figura 15. Relação estrutura-atividade antitubulina dos derivado de CA4 (7)

\section{Referências Bibliográficas}

${ }^{1}$ Sítio do Instituto Nacional do Câncer. INCA. Disponível em: <http://www.inca.gov.br>. Acesso em: 10 de maio de 2014.

${ }^{2}$ Brandão, H. N.; David, J. P.; Couto, R. D.; Nascimento, J. A. P.; David, J. M. Química e farmacologia de quimioterápicos antineoplásicos derivados de plantas. Química Nova 2010, 33, 1359. [CrossRef]

${ }^{3}$ Sítio da World Health Organization. WHO. Disponivel em: <http://www.who.int>. Acesso em: 20 junho 2014.

${ }^{4} 4$ Sítio do Cancer Trends Progress Report. Disponível em: $<$ http://progressreport.concer.gov $>$. Acesso em: 10 maio 2014.

${ }^{5}$ Warner, S. L.; Gray, P. J.; Von Hoff, D. D. Tubulin-associated drug targets: aurora kinases, polo-like kinases, and others. Seminars in Oncology 2006, 33, 436. [CrossRef] [PubMed]

${ }^{6}$ Jordan, M. A.; Wilson, L. Microtubules as a target for anticancer drugs. Nature Reviews Cancer 2004, 4, 253. [CrossRef] [PubMed]

${ }^{7}$ Nogales E. Structural insights into microtubule function. Annual Review of Biophysics and Biomolecular Structure 2001, 30, 397. [CrossRef] [PubMed]
${ }^{8}$ Mauer, A. M.; Cohen, E. E.; Ma, P. C.; Kozloff, M. F.; Schwartzberg, L.; Coates, A. I.; Qian, J.; Hagey, A. E.; Gordon, G. B. J. A phase II study of ABT-751 in patients with advanced non-small cell lung cancer. Journal of Thoracic Oncology 2008, 3, 631. [CrossRef] [PubMed]

${ }^{9}$ Trivedi, M.; Budihardjo, I.; Loureiro, K.; Reid, T. R.; Ma, J. D. Epothilones: a novel class of microtubule-stabilizing drugs for the treatment of cancer. Future Oncology 2008, 4, 483. [CrossRef] [PubMed]

${ }^{10}$ Bunnell, C.; Vahdat, L.; Schwartzberg, L.; Gralow, J.; Klimovsky, J.; Poulart, V.; Peck, R.; Thomas, E. Phase I/II study of ixabepilone plus capecitabine in anthracyclinepretreated/resistant and taxane-resistant metastatic breast cancer. Clinical Breast Cancer 2008; 8, 234. [CrossRef] [PubMed]

${ }^{11}$ Graybill, W. S.; Coleman, R. L. Vintafolide: a novel targeted agent for epithelial ovarian cancer. Future Oncology 2014, 10, 541. [CrossRef] [PubMed]

${ }^{12}$ Pappot, H.; Maase, H. V. D.; Ullen, A.; Agerbæk, M. NUCOG. P113 Design of an exploratory phase I study of pemetrexed in addition to vinflunine as second-line treatment in patients with metastatic urothelial cell carcinoma after prior treatment with platinum. European Urology Supplements 2014, 13, 152. [CrossRef] 
${ }^{13}$ Unnati, S.; Ripal, S.; Sanjeev, A.; Niyati, A. Novel anticancer agents from plant sources. Chinese Journal of Natural Medicines 2013, 11, 0016. [CrossRef]

${ }^{14}$ Chan, D.; LaVallee, T.; Zhang, Z.; Zhao, L.; Swartz, G.; Treston, A.; Fogler, W.; Bunn Jr, P. PD-006 2-Methoxyestradiol ME2, Panzem ${ }^{\circledast}$ ) and its new derivatives inhibited lung cancer cells in vitro and prolonged survivals in athymic nude rats with orthotopic lung tumors in vivo. Lung Cancer 2005, 49,S68. [CrossRef]

${ }^{15}$ Downing, K. H. Structural basis for the interaction of tubulin with proteins and drugs that affect microtubule dynamics. Annual Review of Cell and Developmental Biology 2000, 16, 89. [CrossRef] [PubMed]

${ }^{16}$ Jordan, M. A.; Wilson, L. Microtubules and actin filaments: dynamic targets for cancer chemotherapy. Current Opinion in Cell Biology 1998, 10, 1. [CrossRef] [PubMed]

${ }^{17}$ Snyder, J. P.; Nettles, J. H.; Cornett. B.; Downing, K. H.; Nogales. E. The binding conformation of taxol in $\beta$-tubulin: a model based on electron crystallographic density. Proceedings of the National Academy of Sciences 2001, 98, 5312. [CrossRef] [PubMed]

${ }^{18}$ Jordan, M. A.; Margolis, R. L.; Himes, R. H.; Wilson, L. Identification of a distinct class of vinblastine binding sites on microtubules. Journal of Molecular Biology 1986, 187, 61. [CrossRef]

${ }^{19}$ Gigant, B.; Wang, C.; Ravelli, R. B.; Roussi, F.; Steinmetz, M. O.; Curmi, P. A.; Sobel, A.; Knossow, M. Structural basis for the regulation of tubulin by vinblastine. Nature 2005, 435, 519. [CrossRef] [PubMed]

${ }^{20}$ Tozer, G. M.; Kanthou, C.; Parkins, C. S.; Hill, S. A. The biology of the combretastatins as tumour vascular targeting agents. International Journal of Experimental Pathology 2002, 83, 21. [Crossref] [PubMed]

${ }^{21}$ Ducki, S.; Mackenzie, G.; Lawrence, N. J.; Snyder, J. P. Quantitative structure-activity relationship (5D-QSAR) study of combretastatin-like analogues as inhibitors of tubulin assembly. Journal of Medicinal
Chemistry 2005, 48, 457. [CrossRef] [PubMed]

22 Nakagawa-Goto, K.; Chen, C. X.; Hamel, E.; Wu, C. C.; Bastow, K. F.; Brossi, A.; Lee, K. H. Antitumor agents. Part 236: synthesis of water-soluble colchicine derivatives. Bioorganic \& Medicinal Chemistry Letters 2005, 15, 235. [CrossRef] [PubMed]

${ }^{23} \mathrm{Nam}, \mathrm{N}$. H. Combretastatin A-4 analogues as antimitotic antitumor agents. Current Medicinal Chemistry 2003, 10, 1697. [CrossRef] [PubMed]

${ }^{24}$ Hsieh, H. P.; Liou, J. P.; Mahidroo, N. Pharmaceutical design of antimitotic agents based on combretastatins. Current Pharmaceutical Design 2005, 11, 1655. [CrossRef]

${ }^{25}$ Nguyen, T. L.; McGrath, C.; Hermone, A. R.; Burnett, J. C.; Zaharevitz, D. W.; Day, B. W.; Wipf, P.; Hamel, E.; Gussio, R. A Common pharmacophore for a diverse set of colchicine site inhibitors using a structure-based approach. Journal of Medicinal Chemistry 2005, 48, 6107. [CrossRef] [PubMed]

${ }^{26}$ Tron, G. C.; Pirali, T.; Sorba, G.; Pagliai, F.; Busacca, S.; Genazzani, A. A. Medicinal chemistry of combretastatin A4: present and future directions. Journal of Medicinal Chemistry 2006, 49, 3033. [CrossRef] [PubMed]

${ }^{27}$ Cirla, A.; Mann, J. Combretastatins: from natural products to drug discovery. Natural Product Reports 2003, 20, 558. [CrossRef] [PubMed]

${ }^{28}$ Pettit, G. R.; Cragg, G. M.; Herald, D. L.; Schmidt, J. M.; Lohavanijaya, P. Isolation and structure of combretastatin. Canadian Journal of Chemistry 1982, 60, 1374. [CrossRef]

${ }^{29}$ Pettit, G. R.; Singh, S. B.; Niven, M. L.; Hamel, E.; Schmidt, J. M. Isolation, structure and synthesis of combrestatins A-1 and B-I, potent new inhibitors of microtubule assembly, derived from Combretum caffrum. Journal of Natural Products 1987, 50, 119. [CrossRef] [PubMed]

${ }^{30}$ Watt, J. M.; Breyer-Brandwijk, M. G. The medicinal and poisonous plants of southern 
and eastern Africa. 2a. ed., E. and S. Livingston: London, 1962.

${ }^{31}$ Sofowora, A. Medicinal plants and traditional medicine in Africa. Wiley: New York, 1982. .

${ }^{32}$ Pettit, G. R.; Singh, S. B. Isolation, structure and synthesis of combretastatin A-2, A-3 and B-2. Canadian Journal of Chemistry 1987, 65, 2390. [CrossRef]

${ }^{33}$ Hamel E.; Lin, C. M. Interactions of combretastatin, a new plant-derived antimitotic agent, with tubulin. Biochemical Pharmacology 1983, 32, 3864. [CrossRef]

${ }^{34}$ Pettit, G. R.; Singh, S. B.; Schmidt, J. M.; Nixen, M. L.; Hamel, E.; Lin, C. M. Isolation, structure, synthesis and antimitotic properties of combretastatins B-3 and B-4 from Combretum caffrum. Journal of Natural Products 1988, 51, 517. [CrossRef] [PubMed] ${ }^{35}$ Pettit, G. R.; Singh, S. B.; Hamel, E.; Lin, C. M.; Alberts, D. S.; Garcia-Kendall, D. Isolation and structure of the strong growth and tubulin inhibitor combretastatin A-4. Experientia 1989, 45, 209. [CrossRef] [PubMed]

${ }^{36} \mathrm{Li}, \quad$ Q.; Sham, H. L. Discovery and development of antimitotic agents that inhibit tubulin polymerization for the treatment of cancer. Expert Opinion on Therapeutic Patents 2002, 12, 1663. [CrossRef]

${ }^{37}$ Lin, C. M.; Singh, S. B.; Chu, P. S.; Dempcy, R. O.; Schmidt, J. M.; Pettit, G. R.; Hamel, E. Interactions of tubulin with potent natural and synthetic analogs of the antimitotic agent combretastatin: a structure-activity study. Molecular Pharmacology 1988, 34, 200. [PubMed]

${ }^{38}$ Cushman, M.; Nagarathanam, D.; Gopa, D.; Chakraborti, A. K.; Lin, C. M.; Hamel, E. Synthesis and evaluation of stilbene and dihydrostilbene derivatives as potential anticancer agents that inhibit tubulin polymerization. Journal of Medicinal Chemistry 1991, 34, 2579. [CrossRef] [PubMed]

${ }^{39}$ Getahun, Z.; Jurd, L.; Chu, P. S.; Lin, C. M.; Hamel, E. Synthesis of alkoxy-substituted diaryl compounds and correlation of ring separation with inhibition of tubulin polymerization: differential enhancement of inhibitory effects under suboptimal polymerization reaction conditions. Journal of Medicinal Chemistry 1992, 35, 1058. [CrossRef] [PubMed]

${ }^{40}$ Pettit, G. R.; Cragg, G. M.; Sings, S. B. Antineoplastic agents, 122. Constituents of Combretumcaffrum. Journal of Natural Products 1987, 50, 386. [CrossRef] [PubMed] ${ }^{41}$ Lee, L.; Davis, R.; Vanderham, J.; Hills, P.; Mackay, H.; Brown, T.; Mooberry, S. L.; Lee, M. 1,2,3,4-Tetrahydro-2-thioxopyrimidine analogs of combretastatin-A4. European Journal of Medicinal Chemistry 2008, 43, 2011. [CrossRef] [PubMed]

${ }^{42}$ Vincent, L.; Kermani, P.; Young, L. M.; Cheng, J.; Zhang, F.; Shido, K.; Lam, G.; Bompais-Vincent, H.; Zhu, Z.; Hicklin, D. J.; Bohlen, P.; Chaplin, D. J.; May, C.; Rafii, S. Combretastatin A4 phosphate induces rapid regression of tumor neovessels and growth through interference with vascular endothelial-cadherin signaling. Journal of Clinical Invesigation 2005, 115, 2992. [CrossRef] [PubMed]

${ }^{43}$ Lin, C. M.; Ho, H. H.; Pettit, G. R.; Hamel, E. Antimitotic natural products combretastatin A-4 and combretastatin A-2: studies on the mechanism of their inhibition of the binding of colchicine to tubulin. Biochemistry 1989, 28, 6984. [CrossRef] [PubMed]

${ }^{44}$ Nandy, P.; Banerjee, S.; Gao, H.; Hui, M. B. V.; Lien, E. J. Quantitative structureactivity relationship analysis of combretastatins: a class of novel antimitotic agents. Pharmaceutical Research 1991, 8, 776. [CrossRef] [PubMed]

${ }^{45}$ Mousset, C.; Giraud, A.; Provot, O.; Hamze, A.; Bignon, J.; Liu, J.; Thoret, S.; Dubois, J.; Brion, J.; Alami, M. Synthesis and antitumor activity of benzils related to combretastatin A-4. Bioorganic \& Medicinal Chemistry Letters 2008, 18, 3266. [CrossRef] [PubMed]

${ }^{46}$ Fürst, R.; Zupkó I.; Berényi, A.; Ecker, G. F.; Rinne, U. Synthesis and antitumor-evaluation of cyclopropyl-containing combretastatin analogs. Bioorganic \& Medicinal Chemistry Letters 2009, 19, 6948. [CrossRef] [PubMed] 
${ }^{47}$ Pettit, G. R.; Rhodes, M. R.; Herald, D. L.; Hamel, E.; Schmidt, J. M.; Pettit, R. K. Antineoplastic agents. 445. Synthesis and evaluation of structural modifications of (Z)and (E)-combretastatin A-4. Journal of Medicinal Chemistry 2005, 48, 4087. [CrossRef] [PubMed]

${ }^{48}$ O’Boyle, N. M.; Carr, M.; Greene, L. M.; Bergin, O.; Nathwani, S. M.; McCabe, T.; Lloyd, D. G.; Zisterer, D. M.; Meegan, M. J. Synthesis and evaluation of azetidinone analogues of combretastatin A-4 as tubulin targeting agents. Journal Medicinal Chemistry 2010, 53, 8569. [CrossRef] [PubMed]

${ }^{49}$ Cushman, M.; Nagarathnam, D.; Gopal, D.; He, H. M.; Lin, C. M.; Hamel, E.; Synthesis and evaluation of analogs of (Z)-1-(4methoxyphenyl)-2-(3,4,5-

trimethoxyphenyl)ethene as potential cytotoxic and antimitotic agents. Journal of Medicinal Chemistry 1992, 35, 2293. [CrossRef] [PubMed]

${ }^{50}$ Gaukroger, K.; Hadfield, J. A.; Lawrence, N. J.; Nolan, S.; McGown, A. T. Structural requirements for the interaction of combretastatins with tubulin: how important is the trimethoxy unit? Organic \& Biomolecular Chemistry 2003, 1, 3033. [CrossRef] [PubMed]

${ }^{51}$ Sackett, D. L. Podophyllotoxin, steganacin and combretastatin: natural products that bind at the colchicine site of tubulin. Pharmacology \& Therapeutics 1993, 59, 163. [CrossRef]

52 Maya, A. B.; Perez-Melero, C.; Mateo, C.; Alonso, D.; Fernandez, J. L.; Gajate, C.; Mollinedo, F.; Peláez, R.; Caballero, E.; Medarde, M. Murther naphthylcombretastatins. An investigation on the role of the naphthalene moiety. Journal of Medicinal Chemistry 2005, 48, 556. [CrossRef] [PubMed]

${ }^{53}$ Pettit, G. R.; Minardi, M. D.; Rosenberg, H. J.; Hamel, E.; Bibby, M. C.; Martin, S. W.; Jung, M. K.; Pettit, R. K.; Cuthbertson, T. J.; Chapuis, J. Antineoplastic agents. 509. Synthesis of fluorcombstatin phosphate and related 3-halostilbenes. Journal of Natural
Products 2005, 68, 1450. [CrossRef] [PubMed]

54 Legault, J.; Gaulin, J. F.; Mounetou, E.; Bolduc, S.; Lacroix, J.; Poyet, P.; C-Gaudreault, $\mathrm{R}$. Microtubule disruption induced in vivo by alkylation of beta-tubulin by 1-aryl-3-(2chloroethyl)ureas, a novel class of soft alkylating agents. Cancer Research 2000, 60, 985. [PubMed]

${ }^{55}$ Fortin, S.; Moreau, E.; Lacroix, J.; Teulade, J.; Patenaude, A.; C-Gaudreault, R. N-Phenyl$N^{\prime}$-(2-chloroethyl)urea analogues of combretastatin A-4: is the $N$-phenyl- $N^{\prime}-(2-$ chloroethyl)urea pharmacophore mimicking the trimethoxy phenyl moiety?. Bioorganic \& Medicinal Chemistry Letters 2007, 17, 2000. [CrossRef] [PubMed]

${ }^{56}$ Moreau, E.; Fortin, S.; Desjardins, M.; Rousseau, J. L. C.; Petitclerc, E.; C.Gaudreault, R. C. Optimized N-phenyl-N'-(2chloroethyl)ureas as potential antineoplastic agents: synthesis and growth inhibition activity. Bioorganic \& Medicinal Chemistry 2005, 13, 6703. [CrossRef] [PubMed]

${ }^{57}$ Arthuis, M.; Pontikis, R.; Chabot, G. G.; Quentin, L.; Scherman, D.; Florent, J. Domino approach to 2-aroyltrimethoxyindoles as novel heterocyclic combretastatin A4 analogues. European Journal of Medicinal Chemistry 2011, 46, 95. [CrossRef] [PubMed] ${ }^{58}$ Lawrence, N. J.; Hepworth, L. A.; Rennison, D.; McGown, A. T.; Hadfield, J. A. Synthesis and anticancer activity of fluorinated analogues of combretastatin A-4. Journal of Fluorine Chemistry 2003, 123, 101. [CrossRef] ${ }^{59}$ Pinney, K. G.; Bounds, A. D.; Dingeman, K. M.; Mocharla, V. P.; Pettit, G. R.; Bai, R.; Hamel, E. A new anti-tubulin agent containing the benzo(b)thiophene ring system. Bioorganic \& Medicinal Chemistry Letters 1999, 9, 1081. [CrossRef] [PubMed]

${ }^{60}$ Pinney, K. G.; Mejia, M. P.; Villalobos, V. M.; Rosenquist, B. E.; Pettit, G. R.; Pascal Verdier-Pinard, P.; Hamel, E. Synthesis and biological evaluation of aryl azide derivatives of combretastatin A-4 as molecular probes for tubulin. Bioorganic \& Medicinal Chemistry 2000, 8, 2417. [CrossRef] 
${ }^{61}$ Ohsumi, K.; Nakagawa, R.; Fukuda, Y.; Hatanaka, T.; Morinaga, Y.; Nihei, Y.; Ohishi, K.; Suga, Y.; Akiyama, Y.; Tsuji, T. Novel combretastatin analogues effective against murine solid tumors: design and structureactivity relationships. Journal of Medicinal Chemistry 1998, 41, 3022. [CrossRef] [PubMed]

${ }^{62}$ Kong, Y.; Grembecka, J.; Edler, M. C.; Hamel, E.; Mooberry, S. L.; Sabat, M.; Rieger, J.; Brown, M. L. Structure-based discovery of a boronic acid bioisostere of combretastatin A-4. Chemistry \& Biology 2005, 12, 1007. [CrossRef] [PubMed]

${ }^{63}$ Holwell, S. E.; Cooper, P. A.; Grosios, K.; Lippert, J. W. 3rd; Pettit, G.; Shnyder, S. D.; Bibby, M. C. Combretastatin A-1 phosphate a novel tubulin-binding agent with in vivo anti vascular effects in experimental tumours. Anticancer Research 2002, 22, 707. [PubMed]

${ }^{64}$ Monk, K. A.; Siles, R.; Hadimani, M. B.; Mugabe, B. E.; Ackley, J. F.; Studerus, S. W.; Edvardsen, K.; Trawick, M. L.; Garner, C. M.; Rhodes, M. R.; Pettit, G. R.; Pinney, K. G. Design, synthesis, and biological evaluation of combretastatin nitrogen-containing derivatives as inhibitors of tubulin assembly and vascular disrupting agents. Bioorganic \& Medicinal Chemistry 2006, 14, 3231. [CrossRef] [PubMed]

${ }^{65}$ Hinnen, P.; Eskens, F. A. L. M. Vascular disrupting agents in clinical development. British Journal of Cancer 2007, 96, 1159. [CrossRef] [PubMed]

${ }^{66}$ Vincent, L.; Kermani, P.; Young, L. M.; Cheng, J.; Zhang, F.; Shido, K.; Lam, G.; Bompais-Vincent, H.; Zhu, Z.; Hicklin, D. J.; Bohlen, P.; Chaplin, D. J.; May, C.; Rafii, S. Combretastatin A4 phosphate induces rapid regression of tumor neovessels and growth through interference with vascular endothelial-cadherin signaling. Journal of Clinical Investigation 2005, 115, 2992. [CrossRef] [PubMed]

${ }^{67}$ Hatanaka, T.; Fujita, K.; Ohsumi, K.; Nakagawa, R.; Fukuda, Y.; Nihei, Y.; Suga, Y.; Akiyama, Y.; Tsuji, T. Novel B-ring modified combretastatin analogues: syntheses and antineoplastic activity. Bioorganic \& Medicinal Chemistry Letters 1998, 8, 3371. [CrossRef] [PubMed]

${ }^{68}$ Maya, A. B.; del Rey, B.; de Clairac, R. P. L.; Caballero, E.; Barasoain, I.; Andreu, J. M.; Medarde, M. Design, synthesis and cytotoxic activities of naphthyl analogues of combretastatin A-4. Bioorganic \& Medicinal Chemistry Letters 2000, 10, 2549. . [CrossRef] [PubMed]

${ }^{69}$ Perez-Melero, C.; Maya, A. B.; del Rey, B.; Pelaez, R.; Caballero, E.; Medarde, M. A new family of quinoline and quinoxaline analogues of combretastatins. Bioorganic \& Medicinal Chemistry Letters 2004, 14, 3771. [CrossRef] [PubMed]

${ }^{70}$ Rasolofonjatovo, E.; Provot, O.; Hamze, A.; Rodrigo, J.; Bignon, J.; Wdzieczak-Bakala, J.; Desravines, D.; Dubois, J.; Brion, J.; Alami, M. Conformationnally restricted naphthalene derivatives type isocombretastatin A-4 and isoerianin analogues: synthesis, cytotoxicity and antitubulin activity. European Journal of Medicinal Chemistry 2012, 52, 22. [CrossRef] [PubMed]

${ }^{71}$ Kong, Y.; Wang, K.; Edler, M. C.; Hamel, E.; Mooberry, S. L.; Paige, M. A.; Brown, M. L. A boronic acid chalcone analog of combretastatin A-4 as a potent antiproliferation agent. Bioorganic \& Medicinal Chemistry 2010, 18, 971. [CrossRef] [PubMed]

${ }^{72}$ Ducki, S.; Forrest, R.; Hadfield, J. A.; Kendall, A.; Lawrence, N. J.; McGown, A. T.; Rennison, D. Potent antimitotic and cell growth inhinitory properties of substituted chalcones. Bioorganic \& Medicinal Chemistry 1998, 8, 1051. [CrossRef] [PubMed]

${ }^{73}$ Metzler, M.; Neumann, H. G.. Epoxidation of the stilbene double bond a major pathway in aminostilbene metabolism. Xenobiotica 1977, 7, 117. [CrossRef] [PubMed]

${ }^{74}$ Miller, T. A.; Bulman, A. L.; Thompson, C. D.; Macdonald, T. L. The synthesis and evaluation of temperature sensitive tubulin toxins. Bioorganic \& Medicinal Chemistry Letters 1999, 9, 407. [CrossRef] [PubMed]

${ }^{75}$ Pettit, G. R.; Toki, B.; Herald, D. L.; VerdierPinard, P.; Boyd, M. R.; Hamel, E.; Pettit, R. 
K. Antineoplastic agents. 379. Synthesis of phenstatin phosphate. Journal of Medicinal Chemistry 1998, 41, 1688. [CrossRef] [PubMed]

${ }^{76}$ Gwaltney II, S. L.; Imade, H. M.; Barr, K. J.; Li, Q.; Gehrke, L.; Credo, R. B.; Warner, R. B.; Lee, J. Y.; Kovar, P.; Wang, J.; Nukkala, M. A.; Zielinski, N. A.; Frost, D.; Ng, S.; Sham, H. L. Novel sulfonate analogues of combretastatin A-4: potent antimitotic agents. Bioorganic \& Medicinal Chemistry Letters 2001, 11, 871. [CrossRef] [PubMed]

${ }_{77}$ Amaral, D. N.; Cavalcanti, B. C.; Bezerra, D. P.; Ferreira, P. M. P.; Castro, R. P.; Sabino, J. R.; Machado, C. M. L.; Chammas, R.; Pessoa, C.; Sant'Anna, C. M. R.; Barreiro, E. J.; Lima, L. $M$. Docking, synthesis and antiproliferative activity of $\mathrm{N}$-acylhydrazone derivatives designed as combretastatin A4 analogues. Plos One 2014, 9, 85380. [CrossRef] [PubMed]

${ }^{78}$ Nakamura, M.; Kajita, D.; Matsumoto, Y.; Hashimoto, Y. Design and synthesis of siliconcontaining tubulin polymerization inhibitors: replacement of the ethylene moiety of combretastatin A-4 with a silicon linker. Bioorganic \& Medicinal Chemistry 2013, 21, 7381. [CrossRef] [PubMed]

${ }^{79}$ Lee, M.; Brockway, O.; Dandavati, A.; Tzou, S.; Sjoholm, R.; Nickols, A.; Babu, B.; Chavda, S.; Satam, V.; Hartley, R. M.; Westbrook, C.; Mooberry, S. L.; Fraley, G.; Lee, M. Design and synthesis of novel enhanced water soluble hydroxyethyl analogs of combretastatin A-4. Bioorganic \& Medicinal Chemistry Letters 2011, 21, 2087. [CrossRef] [PubMed]

${ }^{80}$ Lara-Ochoa, F.; Espinosa-Pérez, G. A new synthesis of combretastatins A-4 and AVE8062. Tetrahedron Letters 2007, 48, 7007. [CrossRef]

${ }^{81}$ LeBlanc, R.; Dickson, J.; Brown, T.; Stewart, M.; Pati, H.; VanDerveer, D.; Arman, H.; Harris, J.; Pennington, W.; Holt, H.; Lee, M. Synthesis and cytotoxicity of epoxide and pyrazole analogs of the combretastatins. Bioorganic \& Medicinal Chemistry 2005, 13, 6025. [CrossRef] [PubMed]

82 Ohsumi, K.; Hatanaka, T.; Fujita, K.; Nakagawa, R.; Fukuda, Y.; Nihei, Y.; Suga, Y.;
Morinaga, Y.; Akiyama, Y.; Tsuji, T. Syntheses and antitumor activity of cis-restricted combretastatins: 5-membered heterocyclic analogues. Bioorganic \& Medicinal Chemistry Letters 1998, 8, 3153. [CrossRef]

${ }^{83}$ Kim, Y.; Nam, N.-H.; You, Y.-J.; Ahn, B.-Z. Synthesis and cytotoxicity of 3,4-diaryl-2(5H)furanones. Bioorganic \& Medicinal Chemistry Letters 2002, 12, 719. [CrossRef] [PubMed]

${ }^{84}$ Wang, L.; Woods, K. W.; Li, Q.; Barr, K. J.; McCroskey, R. W.; Hannick, S. M.; Gherke, L.; Credo, R. B.; Hui, Y.-H.; Marsh, K.; Warner, R. J.; Lee, Y.; Zielinski-Mozng, N.; Frost, D.; Rosenberg, S. H.; Sham, H. L. Potent, orally active heterocycle-based combretastatin A-4 analogues: synthesis, structure-activity relationship, pharmacokinetics, and in vivo antitumor activity evaluation. Journal of Medicinal Chemistry 2002, 45, 1697. [CrossRef] [PubMed]

${ }^{85}$ Ravelli, R. B. G.; Gigant, B.; Curmi, P. A.; Jourdain, I.; Lachkar, S. ; Sobel, A.; Knossow, $M$. Insight into tubulin regulation from a complex with colchicine and a stathmin-like domain. Nature 2004, 428, 198. [CrossRef] [PubMed]

${ }^{86}$ Sun, L.; Vasilevich, N. I.; Fuselier, J. A.; Hocart, S. J.; Coy, D. H. Examination of the 1,4-disubstituted azetidinone ring system as a template for combretastatin A-4 conformationally restricted analogue design. Bioorganic \& Medicinal Chemistry Letters 2004, 14, 2041.[CrossRef] [PubMed]

${ }^{87}$ Johnson, M.; Younglove, B.; Lee, L.; LeBlanc, R.; Holt Jr., H.; Hills, P.; Mackay, H.; Brown, T.; Mooberry, S. L.; Lee, M. Design, synthesis, and biological testing of pyrazoline derivatives of combretastatin-A4. Bioorganic \& Medicinal Chemistry Letters 2007, 17, 5897. [CrossRef] [PubMed]

${ }^{88}$ Ruprich, J.; Prout, A.; Dickson, J.; Younglove, B.; Nolan, L.; Baxi, K. ; LeBlanc, R.; Forrest, L.; Hills, P.; Holt, H.; Mackay, H.; Brown, T.; Mooberry, S.; Lee, M. Design, synthesis and biological testing of cyclohexenone derivatives of combretastatinA4. Letters in Drug Design \& Discovery 2007, 4, 144. [CrossRef] 
${ }^{89}$ Shirai, R.; Takayama, H.; Nishikawa, A.; Koiso, Y.; Hashimoto, Y. Asymmetric synthesis of antimitotic combretadioxolane with potent antitumor activity against multi-drug resistant cells. Bioorganic \& Medicinal Chemistry Letters 1998, 8, 1997. [CrossRef] [PubMed]

${ }^{90}$ Tron, G. C.; Pagliai, F.; Del Grosso, E.; Genazzani, A. A.; Sorba, G. Synthesis and cytotoxic evaluation of combretafurazans. Journal of Medicinal Chemistry 2005, 48, 3260. [CrossRef] [PubMed]

${ }^{91}$ Ganina, O. G.; Daras, E.; Bourgarel-Rey, V.; Peyrot, V.; Andresyuk, A. N.; Finet, J. P.; Fedorov, A. Y.; Beletskaya, I. P.; Combes, S. Synthesis and biological evaluation of polymethoxylated 4-heteroarylcoumarins as tubulin assembly inhibitor. Bioorganic \& Medicinal Chemistry 2008, 16, 8806. [CrossRef] [PubMed]

${ }^{92}$ Liou, J. P.; Chang, Y. L.; Kuo, F. M.; Chang, C. W.; Tseng, H. Y.; Wang, C. C.; Yang, Y. N.; Chang, J. Y.; Lee, S. J.; Hsieh, H. P. Concise synthesis and structure-activity relationships of combretastatin A-4 analogues, 1aroylindoles and 3-aroylindoles, as novel classes of potent antitubulin agents. Journal of Medicinal Chemistry 2004, 47, 4247. [CrossRef] [PubMed]

${ }^{93}$ Fray, M. J.; Bull, D. J.; Cooper, K.; Parry, M. J.; Stefaniak, M. H. Novel antagonists of platelet-activating factor. 2. Synthesis and structure-activity relationships of potent and long-acting heterofused [1,5]benzodiazepine and $[1,4]$ diazepine derivatives of 2-methyl- Iphenylimidazo[4,5-c]pyridin. Journal of Medicinal Chemistry 1995, 38, 3524. [CrossRef] [PubMed]

${ }^{94}$ Carr, M.; Greene, L. M.; Knox, A. J. S.; Lloyd, D. G.; Zistereb, D. M.; Meegan, M. J. Lead identification of conformationally restricted $\beta$-lactam type combretastatin analogues: synthesis, antiproliferative activity and tubulin targeting effects. European Journal of Medicinal Chemistry 2010, 45, 5752. [CrossRef] [PubMed]
${ }^{95}$ Banwell, M. G.; Hamel, E.; Hockless, D. C. R.; Verdier-Pinard, P.; Willis, A. C.; Wong, D. J. 4,5-Diaryl-1H-pyrrole-2-carboxylates as combretastatin A-4/lamellarin $T$ hybrids: synthesis and evaluation as anti-mitotic and cytotoxic agents. Bioorganic \& Medicinal Chemistry 2006, 14, 4627. [CrossRef] [PubMed]

${ }^{96} \mathrm{Hu}$, Y.; Lu, X.; Chen, K.; ,Yan, R.; Li, Q.; Zhu, H. Design, synthesis, biological evaluation and molecular modeling of 1,3,4oxadiazoline analogs of combretastatin-A4 as novel antitubulin agents. Bioorganic \& Medicinal Chemistry 2012, 20, 903. [CrossRef] [PubMed]

${ }^{97}$ Zhou, J.; Jin, J.; Zhang, Y.; Yin, Y.; Chen, X.; $\mathrm{Xu}, \mathrm{B}$. Synthesis and antiproliferative evaluation of novel benzoimidazolecontained oxazole-bridged analogs of combretastatin A-4. European Journal of Medicinal Chemistry 2013, 68, 222. [CrossRef] [PubMed]

${ }^{98}$ Parihar, S.; Kumar, A.; Chaturvedi, K.; Sachan, N. K.; Luqman, S.; Changkija, B.; Manohar, M.; Prakasha, O.; Chandaa, D.; Khana, F.; Chanotiyaa, C. S.; Shankera, K.; Dwivedib, A.; Konwarb, R.; Negi; A. S. Synthesis of combretastatin A4 analogues on steroidal framework and their anti-breast cancer activity. Journal of Steroid Biochemistry \& Molecular Biology 2013, 137, 332. [CrossRef] [PubMed]

${ }^{99}$ Pettit, R. K.; Pettit, G. R.; Hamel, E.; Hogan, F.; Moser, B. R.; Wolf, S.; Pon, S.; Chapuis, J.; Schmidt, J. M. E-Combretastatin and $E$ resveratrol structural modifications: antimicrobial and cancer cell growth inhibitory $\beta$-E-nitrostyrenes. Bioorganic \& Medicinal Chemistry 2009, 17, 6606. [CrossRef] [PubMed]

${ }^{100}$ Zoldakova, M.; Kornyei, Z.; Brown, A.; Biersack, B.; Madarász, M.; Schobert, R. Effects of a combretastatin A4 analogous chalcone and its Pt-complex on cancer cells: a comparative study of uptake, cell cycle and damage to cellular compartments. Biochemical Pharmacology 2010, 80, 1487. [CrossRef] [PubMed]

${ }^{101}$ Belleri, M.; Ribatti, D.; Nicoli, S.; Cotelli, F.; Forti, L.; Vannini, V.; Stivala, L. A.; Presta, M. 
Antiangiogenic and vascular-targeting activity of the microtubule-destabilizing transresveratrol derivative 3,5,4trimethoxystilbene. Molecular Pharmacology 2005, 67, 1451. [CrossRef] [PubMed]

102 Kaffy, J.; Pontikis, R.; Carrez, D.; Croisy, A.; Monneret, C.; Florent, J. Isoxazole-type derivatives related to combretastatin A-4, synthesis and biological evaluation. Bioorganic \& Medicinal Chemistry 2006, 14, 4067. [CrossRef] [PubMed]

103 Ducki, S.; Rennison, D.; Wooa, M.; Kendall, A.; Chabert, J. F. D.; McGownb, A. T.; Lawrence, N. J. Combretastatin-like chalcones as inhibitors of microtubule polymerization. Part 1: synthesis and biological evaluation of antivascular activity. Bioorganic \& Medicinal Chemistry 2009, 17, 7698. [CrossRef] [PubMed]

${ }^{104}$ Ducki, S.; Mackenzie, G.; Greedy, B.; Armitage, S.; Chabert, J. F. D.; Bennett, E.; Nettles, J.; Snyder, J. P.; Lawrence, N. J. Combretastatin-like chalcones as inhibitors of microtubule polymerisation. Part 2: structure-based discovery of alpha-aryl chalcones. Bioorganic \& Medicinal Chemistry 2009, 17, 7711. [CrossRef] [PubMed]

${ }^{105}$ Odlo, K.; Chabert, J. F. D.; Ducki, S.; Gani, O. A. B. S. M.; Sylte, I.; Hansen, T. V. 1,2,3Triazole analogs of combretastatin A-4 as potential microtubule-binding agents. Bioorganic \& Medicinal Chemistry 2010, 18, 6874. [CrossRef] [PubMed]

${ }^{106}$ Babu, B.; Lee, M.; Lee, L.; Strobel, R.; Brockway, O.; Nickols, A.; Sjoholm, R.; Tzou, S.; Chavda, S.; Desta, D.; Fraley, G.; Siegfried, A.; Pennington, W.; Hartley, R. M.; Westbrook, C.; Mooberry, S. L.; Kiakos, K.; Hartley, J. A.; Lee, M. Acetyl analogs of combretastatin A-4: synthesis and biological studies. Bioorganic \& Medicinal Chemistry 2011, 19, 2359. [CrossRef] [PubMed]

107 Li, Y.; Liu, J.; Liu, N.; Shi, D.; Zhou, X.; Lv, J.; Zhu, J.; Zheng, C.; Zhou, Y. Imidazoloneamide bridges and their effects on tubulin polymerization in cis-locked vinylogous combretastatin-A4 analogues: synthesis and biological evaluation. Bioorganic \& Medicinal Chemistry 2011, 19, 3579. [CrossRef] [PubMed]
${ }^{108}$ Nguyen, T. T. B.; Lomberget, T.; Tran, N. C.; Colomb, E.; Nachtergaele, L.; Thoret, S.; Dubois, J.; Guillaume, J.; Abdayem, R.; Haftek, M.; Barret, R. Synthesis and biological evaluation of novel heterocyclic derivatives of combretastatin A-4. Bioorganic \& Medicinal Chemistry Letters 2012, 22, 7227. [CrossRef] [PubMed]

109 Jedhe, G. S.; Paul, D.; Gonnade, R. G.; Santra, M. K.; Hamel, E.; Nguyen, T. L.; Sanjayan, G. J. Correlation of hydrogenbonding propensity and anticancer profile of tetrazole-tethered combretastatin analogues. Bioorganic \& Medicinal Chemistry Letters 2013, 22, 4680. [CrossRef] [PubMed]

${ }^{110}$ Odlo, K.; Hentzen, J.; Chabert, J. F.; Ducki, S.; Gani, O. A. B. S. M.; Sylte, I.; Skrede, M.; Flørenesd, V. A.; Hansen, T. V. 1,5Disubstituted 1,2,3-triazoles as cis-restricted analogues of combretastatin A-4: synthesis, molecular modeling and evaluation as cytotoxic agents and inhibitors of tubulin. Bioorganic \& Medicinal Chemistry 2008, 16, 4829. [CrossRef][PubMed]

${ }^{111}$ Barbosa, E. G.; Bega, L. A. S.; Beatriz, A.; Sarkar, T.; Hamel, E.; do Amaral, M. S.; Lima, D. P. A diaryl sulfide, sulfoxide, and sulfone bearing structural similarities to combretastatin A-4. European Journal of Medicinal Chemistry 2009, 44, 2685. [CrossRef] [PubMed]

112 Rasolofonjatovo, E.; Provot, O.; Hamze, A.; Bignon, J.; Thoret, S.; Brion, J.; Alami, M. Regioselective hydrostannation of diarylalkynes directed by a labile ortho bromine atom: an easy access to stereodefined triarylolefins, hybrids of combretastatin A-4 and isocombretastatin A4. European Journal of Medicinal Chemistry 2010, 45, 3617. [CrossRef] [PubMed]

${ }^{113}$ Ty, N.; Dupeyre, G.; Chabot, G. G.; Seguin, J.; Quentin, L.; Chiaroni, A.; Tillequin, F.; Scherman, D.; Michel, S.; Cachet, X. Structure-activity relationships of indole compounds derived from combretastatin A4: synthesis and biological screening of 5phenylpyrrolo[3,4-a] carbazole-1,3-diones as potential antivascular agents. European Journal of Medicinal Chemistry 2010, 45, 3726. [CrossRef] [PubMed] 
${ }^{114}$ Blanch, N. M.; Chabot, G. G.; Quentin, L.; Scherman, D.; Bourg, S.; Dauzonne, D. In vitro and in vivo biological evaluation of new 4,5disubstituted 1,2,3-triazoles as cisconstrained analogs of combretastatin A4. European Journal of Medicinal Chemistry 2012, 54, 22. [CrossRef] [PubMed]

${ }^{115}$ Kamal, A.; Mallareddy, A.; Ramaiah, M. J.; Pushpavalli, S. N. C. V. L.; Suresh, P.; Kishor,
C.; Murty, J. N. S. R. C.; Rao, N. S.; Ghosh, S.; Addlagatta, A.; Pal-Bhadra, M. Synthesis and biological evaluation of combretastatinamidobenzothiazole conjugates as potential anticancer agents. European Journal of Medicinal Chemistry 2012, 56, 166. [CrossRef] [PubMed] 